DOI: 10.12957/demetra.2015.14665

\title{
Avaliação do sistema de produção e da qualidade microbiológica dos méis coletados no município de Sinop, Mato Grosso, Brasil
}

\section{Evaluation of the production system and microbilogical quality of honeys collected at Sinop, Mato Grosso, Brazil}

\author{
Gleycivani Nunes da Silva' \\ Patrícia Azevedo Castelo Branco do Vale ${ }^{2}$ \\ Francianne Baroni Zandonadi ${ }^{3}$ \\ Regiane de Castro Zarelli Leitzke ${ }^{4}$ \\ Jefferson Banderó ${ }^{5}$ \\ Fernanda Cristina Esteves de Oliveira ${ }^{6}$ \\ I Universidade Federal de Mato Grosso do Sul, \\ Departamento de Farmácia, Centro de Ciências \\ Biológicas e da Saúde. Campo Grande-MS, Brasil. \\ ${ }^{2}$ Faculdade de Ciências Sociais e Aplicadas de \\ Sinop, Departamento de Farmácia. Sinop-MT, \\ Brasil. \\ ${ }^{3}$ Faculdade de Ciências Sociais e Aplicadas de \\ Sinop, Departamento de Biomedicina. Sinop-MT, \\ Brasil. \\ ${ }^{4}$ Universidade Federal de Mato Grosso, \\ Departamento de Farmácia, Instituto de Ciência \\ da Saúde. Sinop-MT, Brasil. \\ ${ }^{5}$ Instituto de Defesa Agropecuária de Mato \\ Grosso/Capacitação Continuada em Apicultura. \\ Sinop-MT, Brasil. \\ ${ }^{6}$ Faculdade de Ciências Sociais Aplicadas de \\ Sinop, Departamento de Enfermagem. Sinop-MT, \\ Brasil. \\ Correspondência/Correspondence \\ Fernanda Cristina Esteves de Oliveira \\ E-mail: fernandaestevesufv@gmail.com
}

\section{Resumo}

O mel, substância de alto valor energético e nutricional, faz parte dos hábitos alimentares mundiais, sendo seu consumo in natura relacionado a várias propriedades benéficas para a saúde. Contudo, durante o sistema de produção, suas características microbiológicas podem ser alteradas por diversas fontes de contaminação, comprometendo sua qualidade. Assim, objetivouse neste estudo avaliar o sistema de produção e a qualidade microbiológica de méis do município de Sinop, Mato Grosso, Brasil. Este foi realizado em dez apiários sem nenhum tipo de selo de autorização para sua comercialização. Uma checklist sobre as boas práticas de fabricação foi aplicada. Amostras dos méis beneficiados foram coletadas para a determinação da presença de coliformes totais. Observou-se uma série de inadequações nos apiários, como: presença de animais domésticos nas proximidades (100\%); entrada proibida de pessoas na área de manipulação da casa do mel (90\%); direcionamento incorreto da fumaça do fumegador no manejo da colmeia (80\%); não utilização pelos manipuladores de uniformes brancos (100\%), sempre limpos e de forma exclusiva (90\%); inexistência de sistema de abastecimento ligado à rede pública (80\%), dentre outras. Contudo, as amostras dos méis não indicaram a presença de coliformes totais, resultado que não atesta sua qualidade higienicossanitária e não isenta os apicultores em melhor se adequarem às boas práticas de fabricação. Portanto, a implantação de programas de controle da qualidade ao longo do sistema de produção e a determinação 
de outros micro-organismos que possam estar presentes no mel se fazem necessárias para garantir a qualidade do produto e aumentar a produtividade.

Palavras-chave: Mel. Apicultura. Coliformes. Higiene Alimentar. Padrão de Identidade e Qualidade para Produtos e Serviços.

\section{Abstract}

Honey is a substance of high energy and nutritional value that is part of the diet of many people in the world, and its fresh consumption related to various beneficial properties for health. However, during the production system their microbiological characteristics can be changed by contamination sources, affecting their quality. This study aimed to evaluate the production system and microbiological quality of honeys collected at Sinop, Mato Grosso, Brazil. This was conducted in 10 apiaries, which did not have any stamp for their marketing. A check-list of questions with good manufacturing practices was applied in apiaries. The samples of benefited honeys were collected to determinate the presence of total coliforms. There were many inadequacies in apiaries as: presence of pets in the vicinity (100\%); banned entry of persons in the area of handling of the honey house (90\%); misdirect the smoke smoker in the management of the hive (80\%); not use the white uniforms (100\%), always clean and exclusively (90\%) by handlers; supply system of absence connected on the public network (80\%), among others. However, samples of honey collected did not indicate the presence of total coliforms, a result which does not certify the hygienic and sanitary quality of this product, and does not exempt beekeepers from best suiting good manufacturing practices Thus, the implementation of quality control programs throughout the production system and the determination of other microorganisms that may be present in honey is needed to ensure the product quality and increase productivity.

Key words: Honey. Beekeeping. Coliforms. Food Hygiene. Identify and Quality Pattern for Products and Services. 


\section{Introdução}

A apicultura foi introduzida no Brasil em 1839, mas foi em 1956 que ocorreu um avanço significativo do ponto de vista agronômico, social e tecnológico, resultado da inserção das abelhas africanas (Apis mellifera scutellata) nos apiários do país. A recuperação e expansão desta atividade somente ocorreram a partir de 1970, tendo como marco a realização do Primeiro Congresso Brasileiro de Apicultura. ${ }^{1}$

O mel, substância de alto valor energético e nutricional, é produzido pelas abelhas melíferas a partir do néctar das flores e faz parte dos hábitos alimentares de muitas pessoas no mundo, sendo seu consumo in natura relacionado a várias propriedades benéficas para saúde, como antimicrobianas, curativas, calmantes, regenerativa de tecidos, estimulantes, dentre outras..$^{2-3}$

No Brasil, o consumo per capita anual é de apenas 60 gramas de mel, enquanto em países como Alemanha é de 2,4 quilos e República Centro-Africana, 3,4 quilos. ${ }^{1,4}$ Atualmente, governos estaduais e prefeituras municipais têm criado políticas públicas para estimular seu consumo, a fim de melhorar a saúde das pessoas, e promover o desenvolvimento da apicultura, diversificando a renda dos agricultores sem agredir o meio ambiente.

Exemplo disso tem sido verificado no município de Conquista D’Oeste, no estado de Mato Grosso. A atividade foi introduzida em 2003, com auxílio da Prefeitura Municipal, e em 2005, apoiada pelo Serviço Brasileiro de Apoio às Micro e Pequenas Empresas (SEBRAE), os apicultores conseguiram investimento do Programa Nacional de Fortalecimento da Agricultura Familiar. Em 2006, estes fundaram a Cooperativa dos Apicultores de Mato Grosso (Apisnorte), com associados em sete municípios da região. A partir de sua criação e de algumas adequações técnicas, foi obtido o Selo do Serviço de Inspeção Sanitária Estadual (SISE/MT), que, em conjunto com o Selo do Serviço de Inspeção Federal (SIF), possibilitou a comercialização dos produtos em todo país. ${ }^{5-6}$ No entanto, esta não é a realidade de muitos apicultores de outros municípios do estado de Mato Grosso, os quais não possuem o SISE/MT e o SIF, impossibilitando a comercialização livre de seu produto. Este fato se deve, na maioria das vezes, às inadequações nas boas práticas de fabricação (BPF) e à falta do entreposto, que são requisitos avaliados pelo Ministério da Agricultura, Pecuária e Abastecimento (MAPA), de forma a garantir a qualidade higienicossanitária e físico-química dos méis, bem como a produtividade dos apiários.

Ressalta-se que, no caso da contaminação microbiológica do mel, esta pode ser devida a fontes primárias (que normalmente ocorre antes do período da colheita, sendo muito difícil de controlar, como: pólen, aparelho digestório das abelhas melíferas, pó, solo e néctar) ou secundária (que ocorre no período pós-colheita, sendo decorrente de fatores modificáveis, tais como manipuladores, contaminação cruzada, equipamentos e instalações). . $^{27-8}$ 
Assim, faz-se necessário identificar e solucionar os possíveis riscos de contaminação do mel desde sua colheita até sua comercialização, uma vez que suas características microbiológicas estarão sempre relacionadas à qualidade deste alimento. ${ }^{8-11}$ Dessa forma, este trabalho teve por objetivo avaliar o sistema de produção e a qualidade de méis coletados no município de Sinop, Mato Grosso, Brasil.

\section{Metodologia}

Tratou-se de um estudo de corte transversal, realizado em apiários situados no município de Sinop, Mato Grosso, Brasil, que não possuíam nenhum tipo de selo para sua comercialização. A seleção dos apiários foi realizada de acordo com a autorização dos apicultores. Dessa forma, inicialmente foram contatados 14 apicultores, sendo que destes apenas dez autorizaram a avaliação de seu sistema de produção e seus méis, que ocorreu durante a fase de colheita e beneficiamento deste, de julho a setembro de 2012.

Nas visitas foi aplicado uma checklist $^{12}$ de BPF no entreposto, com base na Portaria $n^{\circ} 6 / 1985$ do MAPA, que aprova as normas higienicossanitária e tecnológicas para mel, cera de abelhas e derivados. ${ }^{13} \mathrm{O}$ instrumento foi constituído por 60 questões referentes a localização dos apiários, manejo das colmeias, utensílios, equipamentos e materiais apícolas, casa do mel, mel, manipuladores, higienização, manejo de resíduos e abastecimento de água. Para análise dos dados, utilizou-se estatística descritiva, sendo seus resultados expressos em frequência absoluta e relativa em relação à adequação total (atende ao item), adequação parcial (atende parcialmente ao item) e inadequação (não atende ao item).

Também foram coletadas amostras dos méis beneficiados (500g), armazenadas em embalagens de vidro transparentes com tampas rosqueáveis, previamente esterilizadas em autoclave e mantidas à temperatura ambiente ao abrigo de luz.

Para a contagem de coliformes totais, alíquotas de $25 \mathrm{~g}$ de cada amostra de mel foram assepticamente pesadas em vidros erlenmeyer previamente esterilizados por meio de autoclavagem e homogeneizadas com $225 \mathrm{ml}$ de solução salina $0,9 \%$. Diluições $10^{-1}, 10^{-2}$ e $10^{-3}$ foram preparadas em tubos de Durhan contendo 10,0 ml de meio de cultura lactose Broth (HiMedia Laboratories pvt. Ltd. India). Esses tubos foram incubados a $35^{\circ} \mathrm{C} / 48$ horas. Após o período de incubação, naqueles com produção de gás, uma alçada de cada cultura foi transferida para os tubos contendo caldo verde brilhante $2 \%$, conforme metodologia do número mais provável por grama de amostra. ${ }^{14}$ 


\section{Resultados e discussão}

O seguimento do manual de BPF é importante não somente para garantir o aumento na produtividade, mas também a manutenção dos padrões de identidade e qualidade do mel. Verificouse (tabela 1) que a maioria dos apiários avaliados apresentava acesso fácil a pessoas, instalados em áreas sombreadas, com equipamentos e utensílios de aço inoxidável e instalações sanitárias próximas ao local de processamento do mel em boas condições. Os apicultores alimentavam as colmeias antes das floradas e utilizavam produtos de higienização registrados no Ministério da Saúde.

Tabela 1 - Avaliação da adequação quanto à localização dos apiários estudados do município de Sinop, Mato Grosso, Brasil, 2012.

\begin{tabular}{|c|c|c|c|c|c|c|}
\hline \multirow[b]{2}{*}{ Localização do apiário } & \multicolumn{2}{|c|}{ SIM } & \multicolumn{2}{|c|}{$\mathrm{NÃO}$} & \multicolumn{2}{|c|}{ PARCIAL } \\
\hline & $\mathrm{n}$ & $\%$ & $\mathrm{n}$ & $\%$ & $\mathrm{n}$ & $\%$ \\
\hline $\begin{array}{l}\text { O apiário está localizado a mais de } 300 \\
\text { metros de residências, currais, galpões } \\
\text { de criação e estradas? }\end{array}$ & 6 & 60 & 4 & 40 & & \\
\hline O apiário possui acesso fácil a veículos? & 4 & 40 & 5 & 50 & 1 & 10 \\
\hline 3. O apiário possui acesso fácil a pessoas? & 8 & 80 & & & 2 & 20 \\
\hline $\begin{array}{l}\text { 4. O apiário se encontra próximo à fonte } \\
\text { de néctar e pólen naturais? }\end{array}$ & 10 & 100 & & & & \\
\hline $\begin{array}{l}\text { 5. O apiário se encontra próximo à fonte } \\
\text { de água de boa qualidade e de fácil } \\
\text { acesso para as abelhas, a uma distância } \\
\text { entre } 100 \text { e } 500 \text { metros? }\end{array}$ & 5 & 50 & 5 & 50 & & \\
\hline $\begin{array}{l}\text { O apiário está instalado em área } \\
\text { sombreada? }\end{array}$ & 9 & 90 & 1 & 10 & & \\
\hline $\begin{array}{l}\text { 7. O apiário está localizado distante } \\
\text { de fontes de contaminação (esgotos, } \\
\text { depósitos de lixo, etc.)? }\end{array}$ & 8 & 80 & 1 & 10 & 1 & 10 \\
\hline
\end{tabular}

SIM: Atende ao item; NÃO: Não atende ao item; PARCIAL: Atende parcialmente ao item. $\mathrm{n}=$ número 
O sombreamento das colmeias contribui para a preservação das características de cor, umidade, teor de hidroximetilfurfural e reação de invertase e diástase dos méis, na produção de própolis, na minimização do estresse térmico sofrido pelas abelhas em regiões tropicais, onde as temperaturas podem ser superiores a $35^{\circ} \mathrm{C}$, juntamente com a facilidade no fluxo operacional, a utilização de equipamentos adequados para seu beneficiamento e condições higienicossanitárias adequadas. ${ }^{5,15-16}$

Os principais fatores de inadequação encontrados foram difícil acesso para veículos e grande distância aos locais de acesso a água para as abelhas (50\%). A dificuldade de acesso ao apiário aumenta desnecessariamente o tempo gasto com o manejo, com o transporte da produção e, eventualmente com o das colmeias. Além disso, a presença de fonte de água pura próxima ao apiário é fundamental para a manutenção dos enxames (menor gasto energético para colheita), principalmente em regiões de clima quente ${ }^{4,10}$, como no município de Sinop, onde a água é usada para auxiliar na termorregulação e na manutenção das necessidades fisiológicas das abelhas.

Verificou-se (tabela 2) que as principais adequações referentes ao manejo correto das colmeias foram a não realização de coletas das melgueiras em dias chuvosos e a utilização de material carburante do fumegador proveniente de materiais de origem vegetal, como serragem, palhas, etc. (90\%). Esses resultados corroboram estudo ${ }^{17}$ em que foi observado que $85 \%$ dos apicultores realizavam a colheita do mel em dias não chuvosos, evitando o comprometimento da sua qualidade. Quanto às inadequações, tem-se a entrada de pessoas que trabalhavam diretamente com a colheita das melgueiras no campo, na área de manipulação da casa do mel (90\%) e direcionamento incorreto da fumaça do fumegador, a qual em $80 \%$ das vezes era feita diretamente sobre os favos. 
Tabela 2 - Avaliação do correto manejo das colmeias de apiários estudados do município de Sinop, Mato Grosso, Brasil, 2012.

\begin{tabular}{|c|c|c|c|c|c|c|}
\hline \multirow[b]{2}{*}{ Manejo das colmeias } & \multicolumn{2}{|c|}{ SIM } & \multicolumn{2}{|c|}{$\mathrm{NA \tilde {O }}$} & \multicolumn{2}{|c|}{ PARCIAL } \\
\hline & $\mathrm{n}$ & $\%$ & $\mathrm{n}$ & $\%$ & $\mathrm{n}$ & $\%$ \\
\hline $\begin{array}{l}\text { 1. O apicultor alimenta as colmeias antes } \\
\text { das floradas? }\end{array}$ & 7 & 70 & 3 & 30 & & \\
\hline 2. As colmeias possuem tela excluidora? & 5 & 50 & 5 & 50 & & \\
\hline $\begin{array}{l}\text { 3. O apicultor utiliza quadros guardados } \\
\text { de melgueira para a produção? }\end{array}$ & 10 & 100 & & & & \\
\hline $\begin{array}{l}\text { 4. A coleta das melgueiras é realizada em } \\
\text { dias chuvosos? }\end{array}$ & 1 & 10 & 9 & 90 & & \\
\hline $\begin{array}{l}\text { 5. Presença de mel verde (desoperculado) } \\
\text { nos quadros de mel para extração? }\end{array}$ & & & 10 & 100 & & \\
\hline $\begin{array}{l}\text { 6. Ausência de crias em qualquer fase } \\
\text { de desenvolvimento nos quadros de mel } \\
\text { para extração? }\end{array}$ & 2 & 20 & 7 & 70 & 1 & 10 \\
\hline $\begin{array}{l}\text { 7. A fumaça utilizada durante o manejo é } \\
\text { fria, limpa e livre de fuligem? }\end{array}$ & 6 & 60 & 2 & 20 & 2 & 20 \\
\hline $\begin{array}{l}\text { 8. A fumaça do fumegador é direcionada } \\
\text { diretamente sobre os favos? }\end{array}$ & 8 & 80 & 1 & 10 & 1 & 10 \\
\hline $\begin{array}{l}\text { 9. Utiliza como material carburante do } \\
\text { fumegador materiais de origem vegetal } \\
\text { como serragem, palhas, etc.? }\end{array}$ & 9 & 90 & 1 & 10 & & \\
\hline $\begin{array}{l}\text { 10. O apicultor, durante o manejo, usa } \\
\text { roupas adequadas para esta prática } \\
\text { (macacão, luvas, botas e máscara)? }\end{array}$ & 7 & 70 & 3 & 30 & & \\
\hline $\begin{array}{l}\text { 11. As pessoas que trabalham } \\
\text { diretamente com a colheita das } \\
\text { melgueiras no campo entram na área de } \\
\text { manipulação na casa do mel? }\end{array}$ & 9 & 90 & 1 & 10 & & \\
\hline
\end{tabular}

SIM: Atende ao item; NÃO: Não atende ao item; PARCIAL: Atende parcialmente ao item $\mathrm{n}=$ número 
O uso correto da fumaça é essencial para que o manejo das colmeias ocorra de forma segura. Sua função é simular uma situação de perigo (ocorrência de incêndio), na qual as abelhas irão se preparar para abandonar o local, ingerindo o máximo de alimento possível, e consequentemente, promovendo aumento de seu peso e maior distensão abdominal, o que irá dificultar seus movimentos para a utilização do ferrão. ${ }^{2,18}$

Observou-se (tabela 3) que os maiores percentuais de adequação referentes aos equipamentos, utensílios e materiais apícolas utilizados estavam relacionados à aquisição de materiais específicos para a manipulação do mel, em que $80 \%$ dos apiários possuíam centrífugas de aço inoxidável, filtros constituídos de tela de aço inoxidável ou fio de náilon com malhas nos limites de 40 a 80 mesh e embalagens para o acondicionamento do mel em material plástico atóxico, vidro ou outros, com SIF. No entanto, também foram detectadas inadequações relacionadas aos equipamentos e seu uso correto, ou seja, durante a centrifugação do mel em $70 \%$ dos locais de beneficiamento as centrífugas não eram devidamente fechadas e em metade destes locais $(n=5)$ não havia mesa de desoperculação de aço inoxidável.

Tabela 3 - Avaliação da adequação dos equipamentos, utensílios e materiais apícolas utilizados nos apiários estudados do município de Sinop, Mato Grosso, Brasil, 2012.

\begin{tabular}{|c|c|c|c|c|c|c|}
\hline \multirow[b]{2}{*}{$\begin{array}{l}\text { Equipamentos, utensílios e materiais } \\
\text { apícolas }\end{array}$} & \multicolumn{2}{|c|}{ SIM } & \multicolumn{2}{|c|}{ NÃO } & \multicolumn{2}{|c|}{ PARCIAL } \\
\hline & $\mathrm{n}$ & $\%$ & $\mathrm{n}$ & $\%$ & $\mathrm{n}$ & $\%$ \\
\hline 1. O apicultor utiliza formão de inox? & 6 & 60 & 4 & 40 & & \\
\hline $\begin{array}{l}\text { 2. O apicultor utiliza fumegador em } \\
\text { inox? }\end{array}$ & 7 & 70 & 2 & 20 & 1 & 10 \\
\hline $\begin{array}{l}\text { 3. A casa do mel possui garfo } \\
\text { desoperculador em aço inox? }\end{array}$ & 2 & 20 & 1 & 10 & 7 & 70 \\
\hline $\begin{array}{l}\text { 4. A mesa de desoperculação é em aço } \\
\text { inoxidável? }\end{array}$ & 5 & 50 & 5 & 50 & & \\
\hline 5. As centrífugas são em aço inoxidável? & 8 & 80 & 2 & 20 & & \\
\hline $\begin{array}{l}\text { 6. Durante a centrifugação, a centrífuga } \\
\text { é mantida fechada? }\end{array}$ & 3 & 30 & 7 & 70 & & \\
\hline $\begin{array}{l}\text { 7. Os tanques de decantação são em aço } \\
\text { inoxidável ou material plástico atóxico? }\end{array}$ & 6 & 60 & 4 & 40 & & \\
\hline
\end{tabular}




\begin{tabular}{|c|c|c|c|c|c|c|}
\hline \multirow[b]{2}{*}{$\begin{array}{l}\text { Equipamentos, utensílios e materiais } \\
\text { apícolas }\end{array}$} & \multicolumn{2}{|c|}{ SIM } & \multicolumn{2}{|c|}{ NÃO } & \multicolumn{2}{|c|}{ PARCIAL } \\
\hline & $\mathrm{n}$ & $\%$ & $\mathrm{n}$ & $\%$ & $\mathrm{n}$ & $\%$ \\
\hline $\begin{array}{l}\text { 8. Os filtros utilizados são de tela de aço } \\
\text { inoxidável ou fio de náilon com malhas } \\
\text { nos limites de } 40 \text { a } 80 \text { mesh? }\end{array}$ & 8 & 80 & 2 & 20 & & \\
\hline $\begin{array}{l}9 . O \text { apicultor utiliza material filtrante de } \\
\text { pano durante a filtração? }\end{array}$ & 4 & 40 & 6 & 60 & & \\
\hline $\begin{array}{l}\text { 10. O apicultor utiliza como meio } \\
\text { filtrante do mel meia de nylon feminina? }\end{array}$ & 6 & 60 & 3 & 30 & 1 & 10 \\
\hline $\begin{array}{l}\text { 11. A localização dos equipamentos } \\
\text { atende a um bom fluxo operacional, } \\
\text { observando os detalhes relativos à } \\
\text { facilidade de higienização? }\end{array}$ & 3 & 30 & 5 & 50 & 2 & 20 \\
\hline $\begin{array}{l}\text { 12. As embalagens para o } \\
\text { acondicionamento do mel são fabricadas } \\
\text { de material plástico atóxico, vidro ou } \\
\text { outros aprovados pelo SIF? }\end{array}$ & 8 & 80 & 2 & 20 & & \\
\hline
\end{tabular}

SIM: Atende ao item; NÃO: Não atende ao item; PARCIAL: Atende parcialmente ao item $\mathrm{n}=$ número

O uso incorreto da centrífuga durante o processamento pode contribuir para o aumento da umidade do produto, uma vez que o mel possui alta higroscopicidade ${ }^{19}$, e assim favorecer a proliferação de micro-organismos deteriorantes. Além disso, a inadequação quanto à localização dos equipamentos, não proporcionando bom fluxo operacional, principalmente quanto à facilidade de higienização, e a inexistência de mesa de desoperculação de aço inoxidável podem representar possíveis fontes de contaminação durante o processamento do mel. ${ }^{20}$

A principal inadequação observada (tabela 4) em todos os locais de processamento do mel (100\%) foi a presença de animais domésticos ou de criação nas proximidades, o que pode resultar na contaminação do alimento, principalmente por material fecal, ${ }^{20}$ além da inexistência de instalações sanitárias dotadas de produtos destinados a higiene pessoal (70\%). Entre os maiores percentuais de adequação referente à casa do mel, pode-se citar que $80 \%$ apresentavam as paredes com altura mínima de dois metros e possuíam instalações sanitárias em boas condições nas proximidades do local onde era feito o processamento. A inexistência da casa do mel ou local de processamento 
dos méis foi constatada em $70 \%$ dos apiários avaliados. Naqueles que a possuíam (90\% dos casos), as portas não eram metálicas ou revestidas de material impermeável, de largura suficiente para atender adequadamente aos trabalhos e trânsito fácil, e as paredes não eram de alvenaria, revestidas com azulejos, cerâmica industrial ou similar, em cores claras, ou outro revestimento que confira perfeita impermeabilização.

Tabela 4 - Avaliação da adequação da casa do mel ou local de processamento dos apiários estudados do município de Sinop, Mato Grosso, Brasil, 2012.

\begin{tabular}{|c|c|c|c|c|c|c|}
\hline \multirow[b]{2}{*}{ Casa do mel ou local de processamento } & \multicolumn{2}{|c|}{ SIM } & \multicolumn{2}{|c|}{ NÃO } & \multicolumn{2}{|c|}{ PARCIAL } \\
\hline & $\mathrm{n}$ & $\%$ & $\mathrm{n}$ & $\%$ & $\mathrm{n}$ & $\%$ \\
\hline 1. O apicultor possui casa do mel? & 2 & 20 & 7 & 70 & 1 & 10 \\
\hline $\begin{array}{l}\text { 2. Ausência nas proximidades de animais } \\
\text { domésticos ou animais de criação? }\end{array}$ & & & 10 & 100 & & \\
\hline $\begin{array}{l}\text { 3. Ausência nas proximidades de } \\
\text { utensílios utilizados em práticas } \\
\text { agrícolas? }\end{array}$ & 5 & 50 & 5 & 50 & & \\
\hline $\begin{array}{l}\text { 4. Ausência dentro do local de utensílios, } \\
\text { roupas, etc. pendurados na parede? }\end{array}$ & 2 & 20 & 8 & 80 & & \\
\hline $\begin{array}{l}\text { 5. Existência de instalações sanitárias } \\
\text { em boas condições nas proximidades do } \\
\text { local? }\end{array}$ & 8 & 80 & 1 & 10 & 1 & 10 \\
\hline $\begin{array}{l}\text { 6. Instalações sanitárias dotadas } \\
\text { de produtos destinados à higiene } \\
\text { pessoal: sabonete líquido inodoro e/ } \\
\text { ou antisséptico, toalhas de papel não } \\
\text { reciclado para as mãos? }\end{array}$ & 2 & 20 & 7 & 70 & 1 & 10 \\
\hline $\begin{array}{l}\text { 7. O apicultor tem hábito de anotar a } \\
\text { produção de cada colmeia, como também } \\
\text { a produção de cada safra? }\end{array}$ & 2 & 20 & 6 & 60 & 2 & 20 \\
\hline $\begin{array}{l}\text { 8. O espaço é suficiente para a instalação } \\
\text { de equipamentos e estocagem do mel? }\end{array}$ & 3 & 30 & 6 & 60 & 1 & 10 \\
\hline
\end{tabular}




\begin{tabular}{|c|c|c|c|c|c|c|}
\hline \multirow[b]{2}{*}{ Casa do mel ou local de processamento } & \multicolumn{2}{|c|}{ SIM } & \multicolumn{2}{|c|}{ NÃO } & \multicolumn{2}{|c|}{ PARCIAL } \\
\hline & $\mathrm{n}$ & $\%$ & $\mathrm{n}$ & $\%$ & $\mathrm{n}$ & $\%$ \\
\hline $\begin{array}{l}\text { 9. As janelas possuem telas e são limpas } \\
\text { pelo menos quinzenalmente? }\end{array}$ & 2 & 20 & 5 & 50 & 3 & 30 \\
\hline $\begin{array}{l}\text { 10. As paredes são de alvenaria, } \\
\text { revestidas com azulejos, cerâmica } \\
\text { industrial ou similar, em cores claras, ou } \\
\text { outro revestimento que confira perfeita } \\
\text { impermeabilização? }\end{array}$ & & & 9 & 90 & 1 & 10 \\
\hline $\begin{array}{l}\text { 11. O piso é feito de material } \\
\text { impermeável, resistente e fácil } \\
\text { higienização? }\end{array}$ & 7 & 70 & 3 & 30 & & \\
\hline $\begin{array}{l}\text { 12. As paredes da casa do mel medem } \\
\text { altura mínima de dois ( } 2 \text { ) metros? }\end{array}$ & 8 & 80 & 2 & 20 & & \\
\hline $\begin{array}{l}\text { 13. O teto ou forro estão em adequado } \\
\text { estado de conservação (livre de trincas, } \\
\text { rachaduras, umidade e bolor). }\end{array}$ & 8 & 80 & 1 & 10 & 1 & 10 \\
\hline $\begin{array}{l}\text { 14. As portas são metálicas ou revestidas } \\
\text { de material impermeável, de largura } \\
\text { suficiente para atender adequadamente } \\
\text { aos trabalhos e trânsito fácil? }\end{array}$ & & & 9 & 90 & 1 & 10 \\
\hline
\end{tabular}

SIM: Atende ao item; NÃO: Não atende ao item; PARCIAL: Atende parcialmente ao item $\mathrm{n}=$ número

Estudo $^{21}$ realizado na microrregião de Pau dos Ferros, Rio Grande do Norte, de modo similar, verificou poucas casas do mel em funcionamento em que muitos apicultores retiravam o mel em locais improvisados sem as condições higiênicas necessárias. Esta é uma realidade nacional, decorrente do fato de a receita obtida com a venda do mel não ser suficiente, na maioria das vezes, para a construção de um local adequado, onde existam área de recepção, extração, armazenamento, vestiário e instalações sanitárias adequadas para os manipuladores. ${ }^{12}$ 
Observou-se que o mel produzido em $70 \%$ dos apiários não era parcial ou totalmente transportado desde a fonte de produção aos entrepostos em embalagens adequadas e específicas para a finalidade, fechadas e protegidas do sol, chuva e poeira. Cerca de $60 \%$ das embalagens contendo mel não eram alocadas devidamente sobre estrados de madeira ou outro material, impedindo o contato direto com o piso, e $60 \%$ dos quadros de mel, depois de coletados, não eram acondicionados em material próprio para transporte, evitando o contato destes com o solo (tabela 5).

Tabela 5 - Avaliação da adequação dos méis produzidos e de seus manipuladores em apiários estudados do município de Sinop, Mato Grosso, Brasil, 2012.

\begin{tabular}{|c|c|c|c|c|c|c|}
\hline & \multicolumn{2}{|c|}{ SIM } & \multicolumn{2}{|c|}{ NÃO } & \multicolumn{2}{|c|}{ PARCIAL } \\
\hline & $\mathrm{n}$ & $\%$ & $\mathrm{n}$ & $\%$ & $\mathrm{n}$ & $\%$ \\
\hline \multicolumn{7}{|l|}{ Mel } \\
\hline $\begin{array}{l}\text { 1. Os quadros de mel, depois de colhidos, } \\
\text { são colocados em material próprio para } \\
\text { transporte, evitando o contato com o solo? }\end{array}$ & 4 & 40 & 3 & 30 & 3 & 30 \\
\hline $\begin{array}{l}\text { 2. As melgueiras, ao chegarem na casa } \\
\text { do mel, são colocadas sobre estrados } \\
\text { devidamente limpos, que impeçam seu } \\
\text { contato com o solo? }\end{array}$ & 4 & 40 & 4 & 40 & 2 & 20 \\
\hline $\begin{array}{l}\text { 3. O mel é armazenado de forma a não } \\
\text { receber luz solar direta? }\end{array}$ & 5 & 50 & 3 & 30 & 2 & 20 \\
\hline $\begin{array}{l}\text { 4. As embalagens contendo mel são } \\
\text { colocadas sobre estrados de madeira ou } \\
\text { outro material, impedindo o contato com } \\
\text { o piso? }\end{array}$ & 5 & 50 & 4 & 40 & 1 & 10 \\
\hline $\begin{array}{l}\text { 5. O mel é transportado desde a fonte de } \\
\text { produção aos entrepostos em embalagens } \\
\text { adequadas e específicas para a finalidade, } \\
\text { fechadas e protegidas do sol, chuva e } \\
\text { poeira? }\end{array}$ & & & & & 2 & 20 \\
\hline
\end{tabular}




\begin{tabular}{|c|c|c|c|c|c|c|}
\hline & \multicolumn{2}{|c|}{ SIM } & \multicolumn{2}{|c|}{ NÃO } & \multicolumn{2}{|c|}{ PARCIAL } \\
\hline & $\mathrm{n}$ & $\%$ & $\mathrm{n}$ & $\%$ & $\mathrm{n}$ & $\%$ \\
\hline \multicolumn{7}{|l|}{ Manipuladores } \\
\hline $\begin{array}{l}\text { 1. Os funcionários da casa do mel usam } \\
\text { uniformes constituídos de calça e avental } \\
\text { ou macacão, gorro, boné ou touca e botas } \\
\text { ou sapatos impermeáveis, todos em cor } \\
\text { branca? }\end{array}$ & & & 10 & 100 & & \\
\hline $\begin{array}{l}\text { 2. Os uniformes estão sempre limpos e } \\
\text { são de uso exclusivo no estabelecimento, } \\
\text { não se permitindo a saída de funcionários } \\
\text { trajando seus uniformes de trabalho? }\end{array}$ & & & 9 & 90 & 1 & 10 \\
\hline $\begin{array}{l}\text { 3. Os manipuladores costumam tomar } \\
\text { banho antes de começar o trabalho? }\end{array}$ & 6 & 60 & 4 & 40 & & \\
\hline $\begin{array}{l}\text { 4. Os manipuladores apresentam as unhas } \\
\text { sempre cortadas e livres de esmaltes? }\end{array}$ & 9 & 90 & & & 1 & 10 \\
\hline $\begin{array}{l}\text { 5. Os manipuladores usam brincos, } \\
\text { relógios, anéis, pulseiras, amuletos e } \\
\text { outras joias dentro da casa do mel? }\end{array}$ & 2 & 20 & 8 & 80 & & \\
\hline
\end{tabular}

SIM: Atende ao item; NÃO: Não atende ao item; PARCIAL: Atende parcialmente ao item $\mathrm{n}=$ número

Esses resultados apontam o risco de contaminação biológica durante o sistema de produção do mel por micro-organismos presentes no solo, os quais são capazes de induzir e acelerar o processo de fermentação do alimento quando já apresenta alteração no teor de umidade, ${ }^{20}$ proveniente de falhas em seu processamento, como manutenção de centrífugas abertas. Sabe-se que as embalagens dos produtos apícolas devem proteger contra a ação dos agentes físicos, químicos e biológicos, de modo a evitar alterações nas características desejadas pelo mercado consumidor. As mesmas devem ser de material plástico atóxico, vidro ou outros aprovados por órgão competente. ${ }^{22} \mathrm{~A}$ armazenagem das embalagens deve ser feita, obrigatoriamente, em locais com desumidificadores, ${ }^{5}$ protegidos de luz e com controle de temperatura ( 25 a $30^{\circ} \mathrm{C}$ ). 
Em um sistema de produção de alimentos, a higiene pessoal e o fluxo operacional são fatores de suma importância para se evitar a contaminação de alimentos e garantir a qualidade do produto final. O manipulador interfere diretamente na qualidade do alimento, seja como um vetor de microorganismos e/ou na produção incorreta, comprometendo sua segurança higienicossanitária. ${ }^{23}$

Foi constatado que $60 \%$ dos manipuladores possuíam o hábito de tomar banho antes do início do trabalho e $90 \%$ apresentavam as unhas sempre cortadas e livres de esmaltes. Porém, durante a manipulação do produto dentro da casa do mel, 100\% dos funcionários não utilizavam uniformes completos na cor branca (calça e avental ou macacão, gorro, boné ou touca e botas ou sapatos impermeáveis), $90 \%$ não utilizavam os uniformes de modo exclusivo no estabelecimento e era permitida a saída de funcionários trajando seus uniformes de trabalho.

Em outro estudo ${ }^{17}$ observou-se que em apenas $8 \%$ dos locais visitados os manipuladores tomavam banho antes de entrar no local de processamento; $15 \%$ possuíam o hábito de lavar as mãos antes do processamento; $46 \%$ mantinham as unhas cortadas e livres de esmaltes; 23\% usavam uniformes, constituídos por calça, avental, touca e máscara, todos em cor branca e sempre limpos e de uso exclusivo dentro do local de processamento. Constatou-se que em 39\% dos locais de extração do

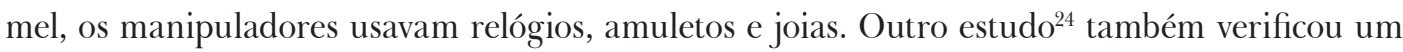
baixo percentual de condições higiênicas satisfatórias dos manipuladores envolvidos na produção de mel do município de Pires do Rio, Goiás. De modo contrário, uma pesquisa ${ }^{21}$ que avaliou as boas práticas na produção de mel em Pau dos Ferros, Rio Grande do Norte, verificou que o apicultor utilizava indumentária adequada (macacão, máscara, luva e bota) e as pessoas que trabalhavam com a colheita das colmeias no campo não entravam na área de manipulação na casa do mel, e as melgueiras também não entravam na área de processamento.

A avaliação da higienização, do manejo de resíduos e do abastecimento de água (tabela 6) mostrou que $70 \%$ dos apiários utilizavam produtos de higienização registrados no Ministério da Saúde. Por outro lado, $80 \%$ dos locais de processamento não possuíam sistema de abastecimento ligado à rede pública; $70 \%$ não tinham produtos de higienização identificados e guardados em local adequado e $60 \%$ não realizavam a retirada frequente dos resíduos da área de processamento, evitando focos de contaminação. 
Tabela 6 - Avaliação da higienização, manejo de resíduos e o abastecimento de água dos apiários estudados do município de Sinop, Mato Grosso, Brasil, 2012.

\begin{tabular}{|c|c|c|c|c|c|c|}
\hline & \multicolumn{2}{|c|}{ SIM } & \multicolumn{2}{|c|}{ NÃO } & \multicolumn{2}{|c|}{ PARCIAL } \\
\hline & $\mathrm{n}$ & $\%$ & $\mathrm{n}$ & $\%$ & $\mathrm{n}$ & $\%$ \\
\hline \multicolumn{7}{|l|}{ Higienização } \\
\hline $\begin{array}{l}\text { 1. Frequência de higienização das } \\
\text { instalações adequada? }\end{array}$ & 4 & 40 & 1 & 10 & 5 & 50 \\
\hline $\begin{array}{l}\text { 2. Produtos de higienização } \\
\text { regularizados no Ministério da Saúde? }\end{array}$ & 7 & 70 & & & 3 & 30 \\
\hline $\begin{array}{l}\text { 3. Produtos de higienização identificados } \\
\text { e guardados em local adequado? }\end{array}$ & 1 & 10 & 7 & 70 & 2 & 20 \\
\hline \multicolumn{7}{|l|}{ Manejo de Resíduos } \\
\hline $\begin{array}{l}\text { 1. Recipientes para coleta de resíduos } \\
\text { no interior do estabelecimento de } \\
\text { fácil higienização e transporte, } \\
\text { devidamente identificados e higienizados } \\
\text { constantemente; uso de sacos de lixo } \\
\text { apropriados? }\end{array}$ & 1 & 10 & 6 & 60 & 3 & 30 \\
\hline $\begin{array}{l}\text { 2. Retirada frequente dos resíduos da } \\
\text { área de processamento, evitando focos de } \\
\text { contaminação? }\end{array}$ & 3 & 30 & 6 & 60 & 1 & 10 \\
\hline
\end{tabular}

Abastecimento de Água
$\begin{aligned} & \text { 1. Sistema de abastecimento ligado à } \\ & \text { rede pública? }\end{aligned}$

SIM: Atende ao item; NÃO: Não atende ao item; PARCIAL: Atende parcialmente ao item n=número 
Em função de não possuírem abastecimento público, os apicultores optam por perfurarem em suas propriedades poços semiartesianos, devido ao baixo custo e facilidade. Assim, a captação de água do aquífero livre fica mais vulnerável à contaminação. ${ }^{25}$ A presença de água tratada é um dos pontos importantes para a garantia da qualidade higienicossanitária do alimento, impedindo que micro-organismos veiculem durante a limpeza dos ambientes, equipamentos, utensílios, veículos de transporte e higiene dos manipuladores. ${ }^{26}$

Ressalta-se que, apesar das várias inadequações observadas nos apiários avaliados, em nenhuma das amostras dos méis coletados foi detectada a presença de coliformes totais, não necessitando realizar a prova para Escherichia coli. O resultado negativo para a presença de fungos e leveduras nas mesmas amostras ${ }^{27}$ vem agregar informações sobre a qualidade microbiológica dos méis do município de Sinop.

Resultado semelhante foi constatado em estudo no Vale do Taquari, Rio Grande do Sul, no qual se observou a ausência dos principais contaminantes característicos do alimento, tais como Staphylococcus aureus, Salmonella spp., Clostridium botulinum e coliformes totais e termotolerantes nas amostras de mel avaliadas, além das baixas contagens observadas de micro-organismos aeróbios e mesófilos, resultado atribuído pelos autores à característica antibacteriana do produto ${ }^{28}$ Estudos similares $^{9,29-30}$ também não verificaram a presença de coliformes totais em amostras de méis coletadas nos estados de Minas Gerais, Rio de Janeiro e Paraná, respectivamente. Contudo, em outra pesquisa $^{7}$ foi detectada a presença de coliformes totais e termotolerantes, bolores, fungos e leveduras em amostras de méis coletados no município de Parintins, Amazonas. Neste estudo, os autores não avaliaram a cadeia de produção e sugeriram que os resultados estiveram atrelados aos períodos iniciais da safra, quando as flores ainda são escassas e as abelhas precisam buscar alimentos em outros locais próximos a criadouros pecuaristas, contaminando, assim, os méis.

Apesar de todas estas análises serem de suma importância para garantir a qualidade do mel e a saúde do consumidor, estas não estão contempladas pela regulamentação técnica proposta pela Portaria n67/1997 do $\mathrm{MAPA}^{31}$ e pela instrução normativa $\mathrm{n}^{\circ} 11 / 2000,{ }^{32}$ o que deve ser revisto. ${ }^{33}$

A microbiota inerente ao mel não interfere na qualidade do mesmo por não serem patogênicos. ${ }^{34}$ No entanto, os coliformes a $35^{\circ} \mathrm{C}$ e a $45^{\circ} \mathrm{C}$, bem como os bolores e leveduras, são indicativos higienicossanitários associados à manipulação e infraestrutura dos apiários, podendo ser causadores de enfermidades. Portanto, mais estudos devem ser realizados para avaliar a cadeia de produção do mel, uma vez que a utilização de boas práticas apícolas está intimamente associada à existência de infraestrutura produtiva adequada, sobtetudo à existência de Unidade de Extração de Produtos Apícolas (casas do mel). ${ }^{35-36}$ 


\section{Conclusão}

A implantação de programas de controle da qualidade ao longo do sistema de produção e a determinação de outros micro-organismos que possam estar presentes no mel, como leveduras, bolores, Staphylococcus aureus, Salmonella spp. e Clostridium botulinum se fazem necessárias para garantir a qualidade final do produto e aumentar a produtividade, garantindo os lucros. Os resultados negativos para contaminação por coliformes totais verificadas no presente trabalho não isentam a responsabilidade dos apicultores em melhor se adequarem às BPF e não atestam a qualidade higienicossanitária deste produto.

Além disso, vale destacar que a apicultura é extremamente relevante para a agricultura familiar, uma vez que garante a polinização dos cultivos, a produção de alimentos para as famílias e fixação das mesmas no local, inclusão social e geração de renda e emprego. Deve haver esforços do poder público local que contemplem o incentivo à adequação desses apicultores as BPF e, consequentemente, ao melhor desenvolvimento das funções de comercialização.

\section{Agradecimentos}

Aos apicultores do munícipio de Sinop, MT, pela colaboração e ao Altivo de Souza e Souza por seu apoio técnico nas análises microbiológicas e ao Jackson Dias Ferreira pelo auxílio na realização das coletas.

\section{Referências}

1. Serviço Brasileiro de Apoio às Micro e Pequenas Empresas. Conheça o histórico da apicultura no Brasil [Internet]. Sebrae Nacional; 2015. Disponível em: http://www.sebrae.com.br/sites/PortalSebrae/ artigos/Conheça-o-histórico-da-apicultura-no-Brasil

2. Pires RMC. Qualidade do mel de abelhas Apis mellifera Linnaeus, 1758 produzido no Piauí [dissertação] Teresina: Universidade Federal do Piauí; 2011.

3. Cruz CBN, Pieri FA, Carvalho-Zilse GA, Orlandi PP, Nunes-Silva CG, Leomil L. Antimicrobial activity of honeys from two stingless honeybee species and Apis mellifera (Hymenoptera: Apidae) against pathogenic microorganisms. Acta Amazônica 2014; 44(2):287-290.

4. Empresa Brasileira de Pesquisa Agropecuária. Boas práticas de manipulação na colheita de mel [Internet]. Teresina: Embrapa; 2002. Acesso em: 20 ago. 2014. Disponível em: http//www.cpamn. embrapa.br/Publicacoes/ct/ct140.pdf 
5. Souza DC. Apicultura: manual do agente de desenvolvimento rural. 2 edição. Brasília: SEBRAE; 2006.183 p.

6. Oliveira LJ, Rauschkolb AS, Figueiredo AMR. Transações e governança na apicultura de Mato Grosso: o caso da Apisnorte. Revista de Política Agrícola 2012; 21(4): 20-34.

7. Matos ITSR, Nunes MT, Mota DA. Laureano MMM, Hoshiba MA. Qualidade microbiológica do mel de Melipona sp. produzido na Amazônia Central (Parintins - AM - Brasil). Revista Verde 2011; 6(4):91-95.

8. Santos DC, Oliveira ENA. Características físico-químicas e microbiológicas de méis de Apis mellifera L. provenientes de diferentes entrepostos. Comunicata Scientiae 2013; 4(1):67-74.

9. Silva MBL, chaves JBP, Message D, Gomes JC, Gonçalves MM, Oliveira GL. Qualidade microbiológica de méis produzidos por pequenos apicultores e de méis de entrepostos registrados no Serviço de Inspeção Federal no estado de Minas Gerais. Alim. Nutr. 2008; 19(4):417-420.

10. Silva MBL, Chaves JBP, Valente MER, Gomes JC, Oliveira GF, Message D. Qualidade de méis produzidos por apicultores e méis provenientes de entrepostos registrados no Serviço de Inspeção Federal. Arq. Bras. Med. Vet. Zootec. 2011; 63(4):1043-1045.

11. Gois GC, Lima CAB, Silva LT, Evangelista-Rodrigues A. Composição do mel de Apis mellifera: requisitos de qualidade. Acta Veterinaria Brasilica 2013; 7(2):137-147.

12. Silva MDL. Diagnóstico do sistema de produção e qualidade de mel de Apis mellifera [dissertação]. Viçosa: Universidade Federal de Viçosa; 2007.

13. Brasil. Portaria no 6 de 02 de julho de 1985. Aprova as Normas Higiênico-Sanitárias e Tecnológicas para Mel, Cera de Abelhas e Derivados. Diário Oficial da União, Brasília, 25 jul. 1985.

14. Andrews WH et al. Salmonella. In: Downes FP; Ito K. Compendium of methods for the microbiological examination of foods. 4. ed. Washington: American Public Health Association; 2001. p. 357-380.

15. Lopes MTR, Barbosa AL, Vieira Neto JM, Pereira FM, Camargo RCR, Ribeiro VQ, et al. Alternativas de sombreamento para apiários. Pesq. Agropec. Trop. 2011; 41(3):299-305.

16. Abadio Fianco FDB, Moura LL, Silva IG. Propriedades físicas e químicas do mel de Apis mellifera L. Ciência e Tecnologia de Alimentos 2010; 30(3):706-712.

17. Dutra MB, Chaves JBP, Message D, Silva AF, Gomes JC. Diagnóstico das condições de colheita e processamento de mel de abelhas Apis mellifera. REBRAPA 2011; 2(2):120-127.

18. Pereira FM, Lopes MTR, Camargo RCR, Vilela SLO. Produção de mel [Internet]. Teresina: Embrapa Meio Norte, 2005. Disponível em: http//www.cpamn.embrapa.br/apicultural/mel

19. Crane, E. Learning about honey through fructose. Bee World 1982; 6(2):34-36.

20. Serviço Brasileiro de Apoio às Micro e Pequenas Empresas. Manual de segurança e qualidade para apicultura Brasília: SEBRAE; 2009. 
21. Silva PHA, Leite AM. Boas práticas na produção de mel na microrregião de Pau dos Ferros. HOLOS 2010; 26(5):154-161.

22. Brasil. Ministério da Agricultura e Abastecimento. Instrução Normativa $\mathrm{N}^{\mathrm{o}}$ 3, de 19 de janeiro de 2001. Aprova os regulamentos técnicos de identidade e qualidade de apitoxina, cera de abelha, geleia real, geleia real liofilizada, pólen apícola, própolis e extrato de própolis. Diário Oficial da União, 23 jan. 2001.

23. Santos MOB, Rangel VP, Azeredo DP. Adequação de restaurantes comerciais às boas práticas. Higiene Alimentar 2010; 24(190/191):44-49.

24. Ananias KR. Avaliação das condições de produção e qualidade de mel de abelhas (Apismellifera L.) produzido na microrregião de Pires do Rio, no Estado de Goiás [dissertação] Goiânia: Universidade Federal de Goiás; 2010.

25. Foster S, Hirata R. Determinação do risco de contaminação das águas subterrâneas: um método baseado em dados existentes. Boletim do Instituto Geológico 1993; 10. 92 p.

26. Serviço Nacional de Aprendizagem Industrial. Manual de segurança e qualidade para a apicultura. Brasília: SENAI; 2009. 86 p.

27. Ferreira JD, Oliveira FCE, Mancini CE, Zandonadi FB, Vale PACB. Determinação de fungos filamentosos e leveduras em méis produzidos no município de Sinop, Mato Grosso [Internet]. Biofar: Revista de Biologia e Farmácia 2013; 09(04). Disponível em: http://sites.uepb.edu.br/ biofar/download/v9n4-2013/DETERMINA\%C3\%87\%C3\%83O\%20DE $\% 20$ FUNGOS $\% 20$ FILAMENTOSOS $\% 20$ E $\% 20$ LEVEDURAS $\% 20$ EM $\% 20 \mathrm{M} \% \mathrm{C} 3 \% 89 \mathrm{IS} \% 20$ PRODUZIDOS $\% 20$ NO\%20MUNIC\%C3\%8DPIO\%20DE\%20SINOP,\%20MATO\%20GROSSO.pdf

28. Schlabitz C, Silva SAF, Souza, CFV. Avaliação de parâmetros físico-químicos e microbiológicos em mel. Revista Brasileira de Tecnologia Agroindustrial 2010; 4(1):80-90.

29. Marabet LP. Determinação da atividade de água, teor de umidade e parâmetros microbiológicos em compostos de mel. Oikos: Revista Brasileira de Economia Doméstica 2011; 22(2):213-232.

30. Périco E, Tiuman TS, Lawich MC, Kruger RL. Avaliação microbiológica e físico-química de méis comercializados no município de Toledo, PR. RECEM 2011; 13(3):365-382.

31. Brasil. Portaria DIPOA no 368, de 04 set. 1997. Regulamento técnico sobre as condições higiênicosanitárias e de boas práticas de fabricação para estabelecimentos elaboradores/processadores de alimentos. Diário Oficial da União, 08 set. 1997, Seção 1, p. 19697.

32. Brasil. Instrução Normativa $n^{\circ} 11$ de 20 de outubro de 2000. Aprova o regulamento técnico de identidade e qualidade do mel. Diário Oficial da União, 23 out. 2000.

33. Gomes L.P. Contaminação bacteriana em amostras de méis de Apis mellifera L. comercializados no Estado do Rio de Janeiro [dissertação] Seropédica: Universidade Federal Rural do Rio de Janeiro; 2006.

34. Alves TTL, Meneses ARV, Silva JN, Parente GDL, Holanda Neto JP. Caracterização físico-química e avaliação microbiológica de méis de abelhas nativas do nordeste brasileiro. Revista Verde 2011; 6(3):91-97. 
35. Moura S.G. Boas práticas apícolas e a qualidade do mel de abelhas Apis mellifera Linnaeus, 1758 [tese] Teresina: Universidade Federal do Piauí; 2010.

36. Moura SG, Muratori MCS, Monte AM, Carneiro RM, Souza DC, Alencar LC. Perfil sanitário dos apicultores piauienses quanto às boas práticas apícolas. Scientia Plena 2013; 9(5):1-4.

Recebido: $13 / 2 / 2015$

Revisado: $11 / 3 / 2015$

Aprovado: 28/3/2015 